(c) American Dairy Science Association, 2003.

\title{
A System to Assess Fitness of Dairy Cows Responding to Exercise Training
}

\author{
J. A. Davidson ${ }^{1}$ and D. K. Beede \\ Department of Animal Science, Michigan State University, \\ East Lansing 48824
}

\begin{abstract}
Objectives were to develop a system to administer exercise training to dairy cows, to measure potential physiological indicators of fitness, and to assess physical fitness. Nonlactating, nonpregnant multiparous Holstein cows $(n=19)$ were in one of three exercise training treatments: no exercise; 1 -h exercise; or 2 -h exercise by walking $3 \mathrm{~km} / \mathrm{h}$ every other day for $60 \mathrm{~d}$ in a mechanical walker. Treadmill tests on d 15, 30, 45, and 60 consisted of walking $(5 \mathrm{~km} / \mathrm{h})$ with $1.6 \%$ increases in slope at 3-min intervals until heart rates reached 180 beats per minute (experimentally specified maximum) or until cows refused to walk. Fitness indices analyzed in tests as single datum points at maximal heart rates were length of time of test, heart rate, and plasma L-lactate concentration at end of the test, and change in heart rate and lactate concentration during the test. Exercised ( 1 or $2 \mathrm{~h}$ ) cows had longer times to end of tests than nonexercised cows. Maximal and change in heart rates or plasma lactate during tests did not indicate improved physical fitness. However, when all data were evaluated as repeated measures of day and minute of tests, reductions of heart rates and plasma lactate concentrations were greatest on $\mathrm{d} 60$ between exercised and nonexercised cows indicating improved fitness. Acid-base measurements were not found useful in this study. Changes of heart rates and plasma lactate concentrations over time (repeated measures) of treadmill tests quantified the physical fitness of dairy cows and can be used to compare potential responses to different exercise training treatments in this system.
\end{abstract}

(Key words: exercise, training, physical fitness, acidbase status)

Abbreviation key: BE-B = base excess of blood, BE$\mathbf{E C F}=$ base excess of extracellular fluid, $\mathbf{B P M}=$ beats

Received July 18, 2002.

Accepted April 28, 2003.

Corresponding author: D. K. Beede; e-mail: beede@msu.edu.

${ }^{1}$ Present address: U.S. Dairy Forage Research Center, Prairie du Sac, WI 53578. per minute, HCT = hematocrit, HGB = hemoglobin, $\mathbf{i C a}^{2+}=$ ionized calcium, NaF-KOxalate $=$ sodium fluoride and potassium oxalate, $\mathbf{p} \mathbf{C O}_{2}=$ partial pressure carbon dioxide, $\mathbf{T C O}_{2}=$ total carbon dioxide.

\section{INTRODUCTION}

There is general lack of knowledge about the possible value on health and performance of improved physical fitness of dairy cattle. Physical fitness may be important to the ability of the cow to respond to physiological and metabolic demands associated with the periparturient period. Defining an exercise training system and identifying and characterizing useful indicators of physical fitness is the first step in elucidating possible benefits from exercise training. Physical fitness is defined as "the capacity to successfully meet the present and potential physical challenges of life" (Lamb, 1984). Physiological fitness can be defined as the capacity of bodily functions to complete a task, workload, or challenge of life. Fitness may be evaluated by examining the ability of an animal to maintain homeostasis or steady-state during defined work performed during a given period (workload). After repeated exercise in a defined regimen (exercise training), physical and physiological fitness may be improved. For example, in horses exercised for $5 \mathrm{wk}$, plasma venous lactate concentrations were less during an exercise test compared with values before training (Rodiek et al., 1987). Other indices of fitness at maximum work such as heart frequency in horses (Ehrlein et al., 1973) and cattle (Kuhlmann et al., 1985; Arave et al., 1987), hematological responses of cattle (Piguet et al., 1994), blood plasma hormonal responses in cattle (Blum et al., 1979), and oxygen demand of sheep (Mundie et al., 1991) have been evaluated. Assessment of physical fitness of dairy cows by exercise tests has not been described following extended confinement or exercise training.

The objectives of this study were to develop a system to administer exercise training, to measure and assess possible physiological indicators of fitness with exercise training, and to assess possible changes in physical fitness of dairy cows at intermittent tests during training. The hypothesis was that exercise training improves 
physical fitness of dairy cows. Potential physiological indicators of fitness tested were heart rate, plasma lactate concentrations, and maintenance of acid-base status during given workloads of a test. Estimates of cow (among-cow) and residual (within-cow) variances of these indicators are also reported as potentially useful information for design of future experiments.

\section{MATERIALS AND METHODS}

\section{General Description of System}

The system consisted of a circular mechanical walker for routine exercise training of cows, a treadmill to administer workloads to assess physiological responses and physical fitness, and a heart beat monitoring system.

Mechanical walker for exercise training. The mechanical walker was a modified six-horse commercial walker (Hot to Trot Horsewalkers, Chardon, $\mathrm{OH}$ ). The walker was located $36.5 \mathrm{~m}$ from the tie-stall barn where cows were housed. Exercise training was done with cows in a circular lane built of parallel panels positioned under the arms at the outer circumference of the walker. The circular lane had an outside diameter of $10.8 \mathrm{~m}$, a circumference of $33.8 \mathrm{~m}$, and a width of $90 \mathrm{~cm}$. The walking surface of the circular lane was approximately $20 \mathrm{~cm}$ (depth) of rolled stone covered with geo-textile felt (Cow Carpet TM, S \& R Textiles, Highpoint, NC). The felt was covered with about $15 \mathrm{~cm}$ of fine sand. Six partitions, each hanging from the outer end of an arm, separated cows within the circular lane. Each partition was made of galvanized metal pipe and steel chain. Three $60-\mathrm{cm}$ lengths of $2.5-\mathrm{cm}$ metal pipe were bolted horizontally to three, 245 -cm lengths of 0.5 $\mathrm{cm}$ steel chain. Chain lengths were attached to a $90-$ $\mathrm{cm}$ length of polyvinyl chloride pipe mounted to each arm of the walker. Plywood panels (0.6-cm thick, 56$\mathrm{cm}$ wide, $70-\mathrm{cm}$ long) were attached to the bottom of the chain lengths. The panels helped separate cows and control walking speed. Partitions were flexible enough to pass over a cow's head and back if she refused to continue walking. Cows learned to use the mechanical walker system during two to three, 5- to 10-min training sessions completed about 2 to $3 \mathrm{wk}$ before actual experimentation began.

Treadmill for fitness assessment. The treadmill used to conduct tests was kept at the end of the tiestall barn housing the cows. The overall dimensions of the space on the treadmill in which cows stood and walked was $0.85 \mathrm{~m}$ wide by $4.5 \mathrm{~m}$ long. The cows were confined by padded sidewalls ( $1.2 \mathrm{~m}$ high) and movable end-gates where cows entered and exited via ramps. Originally designed for horses, the treadmill had heavy rubber belting on the walking surface driven by an electric motor with a clutch mechanism (Classic Treadmill Conditioner, W. H. D. Lindsey, Kenilworth, Australia). Near the rear of the space was a movable padded butt bar that was positioned perpendicular between and $18 \mathrm{~cm}$ below the top edge of the sidewalls to help keep cows walking forward at the preset rate of speed of the belt. The speed of the belt could be varied and the slope of the treadmill walking surface could be increased by hydraulic cylinders to increase workloads. Cows were trained to use the treadmill during two or three, 5 - to 10-min practice sessions that occurred following training to use the mechanical walker, but before the beginning of experimentation. During an actual treadmill test, the speed of walking was increased gradually during the first $30 \mathrm{~s}$ until the prescribed rate was achieved.

Measurement of heart rates. Heart beats were recorded every 5 to $15 \mathrm{~s}$ (depending on experiment) via a wireless electrocardiogram monitor (Polar Advantage NV, Polar Electro, Port Washington, NY). The hair of the chest floor and area behind the cow's elbow to the point of her shoulder was clipped to improve skin contact with electrodes. The electrode strap was attached around the girth with a 5 -cm wide elastic strap on the left side of the cow. An outer, wider elastic strap (7.6$\mathrm{cm}$ wide) and felt saddle girth were placed over the electrode to aid in maintaining skin contact while the cow walked. Electrocardiogram gel (Medi-Trace Conductivity Gel, Graphic Controls, Buffalo, NY) was placed on the electrode to skin contact points to insure conductivity of the signal. Care always was taken to reduce poor contact between the electrode and skin. Any electromagnetic disturbance, static electricity, arrhythmia, or too much distance between receiver and transmitter could cause atypical readings. Capability also was available to transmit the electrocardiogram signal to a small data logger about the size of a wristwatch that was attached to the outer elastic strap on the cow; such measurements could be made while cows were walking in the mechanical walker. Data were then later downloaded via an interface through software to a computer (Polar Precision, Polar Electro, Port Washington, NY). During treadmill tests, heart beat signals were transmitted directly to a computer, monitored in real-time, and recorded. Representative graphs of heart rate data are shown when a cow was walking in the mechanical walker (Figure 1) and on the treadmill (Figure 2).

\section{Cows and Exercise Training Treatments}

Animal care and procedures were approved and conducted under standards of the Michigan State University All-University Committee on Animal Use and Care, 


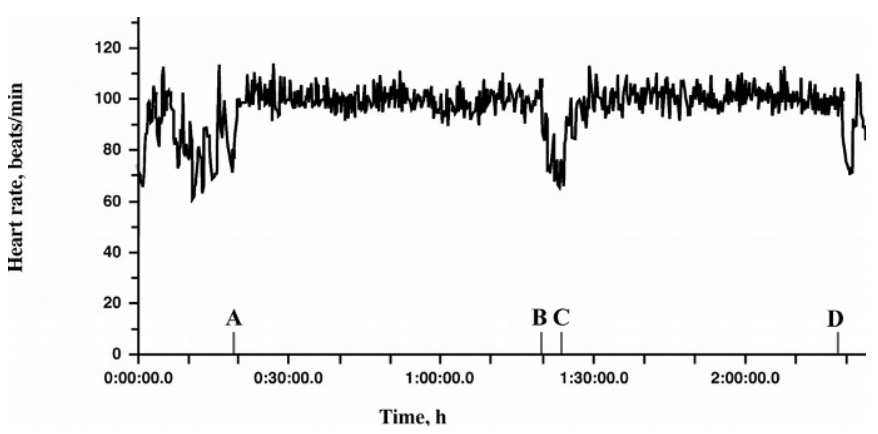

Figure 1. Example of representative data from one cow during exercise in the mechanical walker. Letters in the graph represent the following events: beginning of the first hour of exercise, $\mathbf{A}$; exercise stopped to load additional cows into mechanical walker, B; beginning of second hour of exercise, $\mathbf{C}$; and, cessation of exercise, $\mathbf{D}$.

application number 05/98-081-00 in compliance with National Institutes of Health and the Guide for the Care and Use of Laboratory Animals.

Nineteen nonlactating, nonpregnant multiparous Holstein dairy cows $(751 \pm 22 \mathrm{~kg}$ initial BW) were blocked by parity and BCS (average $3.6 \pm 0.15$ initial $\mathrm{BCS}$ ) and assigned randomly to exercise training treatments: no exercise; 1 -h exercise in the walker at $3 \mathrm{~km} /$ $\mathrm{h}$ (1-h exercise); or, 2 -h exercise at $3 \mathrm{~km} / \mathrm{h}$ (2-h Exercise). Nonlactating, nonpregnant cows were utilized initially to characterize the system and cows' responses, and to gain experience in handling cows in the system. Cows in other physiological states were studied in subsequent research.

Exercise training was completed every other day for $60 \mathrm{~d}$ in the mechanical walker. Cows assigned to each of the three treatments walked about $36.5 \mathrm{~m}$ from the tie-stall barn alley to holding pens $(8.5 \times 3 \mathrm{~m})$ adjacent to the mechanical walker. Cows assigned to no exercise

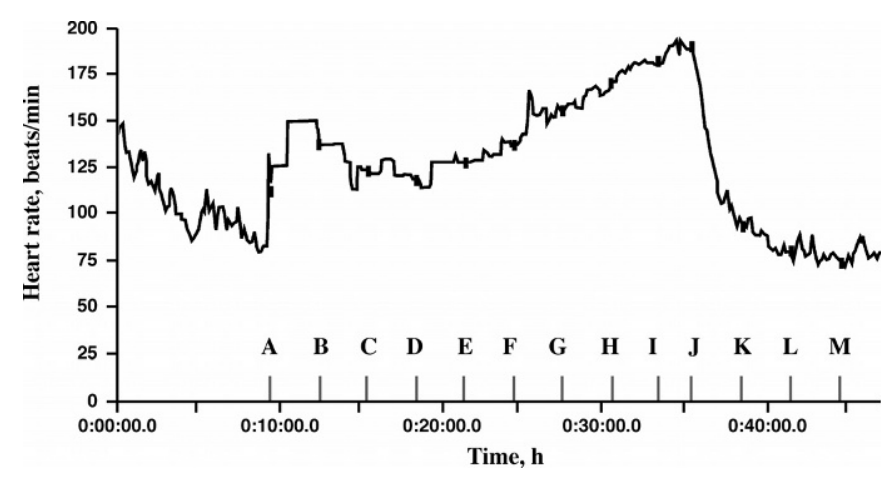

Figure 2. Example of representative data from one cow during a treadmill exercise test. The letters on the graph indicate the beginning of exercise, A; each increase of slope every $3 \mathrm{~min}, \mathbf{B}$ to $\mathbf{I}$; the end of the exercise at which peak heart rate was recorded, J; and, postexercise, $\mathbf{K}$ to $\mathbf{M}$. were placed in holding pens adjacent to the mechanical walker, while cows in the exercise treatments walked. After cows in the 1-h exercise treatment completed their walking, they were moved into the holding pens, while cows in the 2-h exercise treatment walked for an additional hour. This ensured that all cows were exposed to the same environmental conditions and were held from feed and water for the same length of time.

Except during exercise training and standing in holding pens, all cows were kept in tie stalls in a ventilated pole barn with full side walls. They were fed ad libitum once daily a TMR containing $62 \%$ alfalfa haylage, $15 \%$ corn silage, $18 \%$ spelt hulls, $3.8 \%$ soybean meal, plus mineral and vitamins (1.42 Mcal of $\mathrm{NE}_{\mathrm{I}} / \mathrm{kg}, 15.6 \% \mathrm{CP}$, $38.5 \% \mathrm{ADF}$, and $51.7 \% \mathrm{NDF}$, dry basis). Daily DM and water intakes of individual cows were recorded. Body weights and BCS (Wildman et al., 1982) were measured every $15 \mathrm{~d}$. On $\mathrm{d} 0$ and 60 of the experiment, back fat thickness above the 12th and 13th ribs was determined with ultrasound using a linear scan $7.5-\mathrm{MHz}$ probe (Aloka 500 Ultrasound, Corometrics Medical Systems, Inc., Wallingford, CT) (VandeHaar et al., 1999).

\section{Treadmill Tests}

Application of workload and heart rate monitoring. As a bioassay to assess physical fitness and physiological responses, treadmill tests were performed with each cow on d 15, 30, 45, and 60 of the experiment. The test consisted of walking $(5 \mathrm{~km} / \mathrm{h})$ on the treadmill. Slope of the treadmill walking surface increased $1.6 \%$ at 3-min intervals to increase workloads. Therefore, it was possible for a cow to experience six slope changes to a maximum slope of $9.6 \%$ of the walking surface during a test. Heart beats were monitored in real time, recorded every $5 \mathrm{~s}$ with the wireless electrocardiogram and transmitted to computer. The test continued until cows refused to walk (rested on the butt bar) or until heart rates were greater than 180 beats per minute (BPM) for two consecutive 3-min intervals. The heart rate of a cow that refused to walk may not have reached 180 BPM. If heart rate reached at least 165 BPM, a treadmill test was considered a maximal workload challenge. The time from beginning to end of the exercise portion of each test was recorded. Total elapsed time of active work during the treadmill test ranged from 9 to 30 min depending on cow and day of experiment. At the end of walking the treadmill platform was lowered to $0 \%$ slope and the treadmill was stopped; heart beat measurements and blood sampling (at 3-min intervals) continued for $12 \mathrm{~min}$ (the postexercise portion of the test).

Blood sampling and measurements. An indwelling catheter was inserted into the jugular vein $1 \mathrm{~d}$ before 
the treadmill test. Blood $(10 \mathrm{ml})$ was sampled during the final min of each 3-min interval of the exercise and postexercise portions of the test. Blood was transferred to evacuated glass test tubes containing Na-heparin or sodium fluoride/potassium oxalate (NaF-KOxalate) (Vacutainer; Beckton Dickinson Vacutainer Systems, Franklin Lakes, NJ). Blood with Na-heparin was analyzed for $\mathrm{pH}$, partial pressure of carbon dioxide $\left(\mathbf{p} \mathbf{C O}_{2}\right)$, hematocrit (HCT), and concentrations of potassium $\left(\mathbf{K}^{+}\right)$, ionized calcium $\left(\mathbf{i} \mathbf{C a}^{2+}\right)$, and chloride $\left(\mathbf{C l}^{-}\right)$(Stat 5 Profiler, Nova Biochemical, Waltham, MA). From these measurements, the concentrations of bicarbonate $\left(\mathbf{H C O}_{3}{ }^{-}\right)$, total carbon dioxide $\left(\mathbf{T C O}_{2}\right)$, hemoglobin (HGB), base excess of extracellular fluid (BE-ECF), and base excess of blood (BE-B) were computed (Stat 5 Profiler, Nova Biochemical).

Blood with NaF-KOxalate was centrifuged $(2000 \times$ g) within $15 \mathrm{~min}$ of collection and plasma harvested. Plasma was stored at $-20^{\circ} \mathrm{C}$ until analysis for L-lactate concentrations using a lactate oxidase kit modified for use in a 96-well plate reader (Sigma Diagnostics, St. Louis, MO). Intra- and interassay coefficients of variation of the assay were 3.9 and $4.0 \%$, respectively.

\section{Statistical Analyses}

Data were analyzed by the method of ANOVA using mixed model procedures of SAS (1999). The appropriate covariance structure for the repeated measures was determined using goodness-of-fit criteria (Aiaike's information criterion and Schwarz's Bayesian criterion). Unless otherwise described, results are presented as generalized least squares means with standard error of means. The among- and within-animal variance components were estimated using residual maximum likelihood methods of mixed models. Statistical significance was declared at $P<0.05$; trends were noted at $0.05<$ $P<0.15$.

Variation of plasma L-lactate concentrations was not homogeneous across time within day of experiment during all portions of the treadmill test. Therefore, data were transformed via natural logarithmic transformation before statistical analysis. The back-transformed least squares means are presented. The $67 \%$ confidence intervals of back-transformed least squares means were calculated and are plotted.

From data collected during the treadmill tests, maximal indices providing information about physical fitness in response to exercise training were computed and assessed. These indices included: 1) time to end of treadmill test at which maximal heart rate per cow was recorded; 2) maximum heart rate per cow when the treadmill test ended; and, 3) blood plasma L-lactate concentration per cow when the test ended. Addition- ally, responses of heart rate and blood variables across the time of treadmill test were evaluated to compare the patterns, rate, and extent of responses.

The time to end of the treadmill test was analyzed with a mixed model that included random effect of cow, repeated measures effect of day of test, and fixed effects of treatment and two-way interaction of day $\times$ treatment. Orthogonal contrasts to separate treatment means for all dependent variables included: no exercise vs. 1-h exercise and 2-h exercise; and, 1-h exercise vs. 2 -h exercise. Chi-square analysis was used to determine whether treatment affected the probability of completing maximal workloads of the treadmill exercise test.

The frequency of observations for heart rate and blood variables during the exercise portion of tests differed among cows and tests. This was due to differences in time to end of tests because heart rate may have reached the experimentally defined maximum (180 BPM) for some cows more quickly than for others, or some cows may have refused to continue the test beyond a certain time. The maximum possible frequency of observations was $19 / \mathrm{min}$ within a test day including all cows on all treatments. The actual frequency of observations per minute of test was eight or less between 22 to $25 \mathrm{~min}$ for no exercise treatment; between 22 to 27 min for 1-h exercise; and between 22 to 30 min for 2 -h exercise treatment (Figure 3). To illustrate and evaluate the temporal responses and because of the reduced frequency of observations beyond $20 \mathrm{~min}$, the data from 0 to $20 \mathrm{~min}$ of the exercise portion of the test were included in the statistical analyses. The measurement or observation at the final minute of the exercise portion of each test of each cow was used to assess maximal indices (e.g., maximums of heart rate, lactate concentration, and length of time to end of test). This datum point of each cow also was included in analysis of the postexercise portion of the test ( $0 \mathrm{~min}$ ) for each dependent variable.

Heart rates, blood, and plasma variables from 0 to 20 min during the exercise portion of the test and from 0 to 12 min during postexercise portion were analyzed separately. Heart rate data at 5-s intervals were used to calculate the average for each minute during the exercise portion of the test. Because of the rapid decline of heart rates once exercise ceased, heart rate data at 5 -s intervals were averaged for each 15 -s period for the postexercise portion. To account for any missing heart rate measurements during a given minute or 15-s interval, average heart rates were weighted by the number of observed heart rates within a time interval in the mixed model analyses. The mixed model included the random effect of cow nested within treatment, repeated measures of day of experiment and minute of test, and the fixed effect of treatment. All two- and three-way 

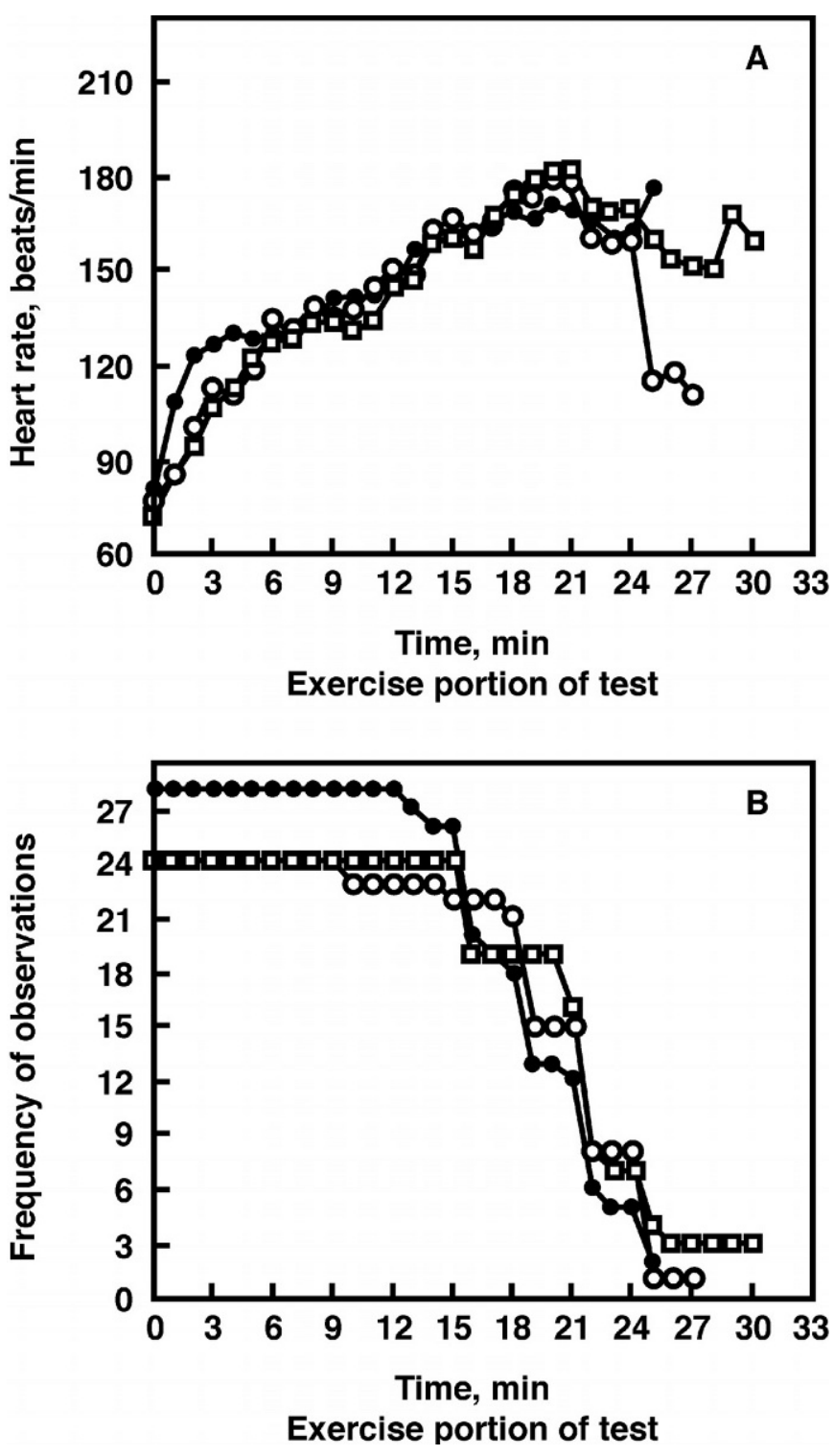

Figure 3. Mean heart rates and frequency of observations during exercise portions of treadmill tests pooled across d 15, 30, 45, and 60 of the experiment. Treatments were no exercise (-), 1-h Exercise $(\bigcirc)$, and 2-h exercise $(\square)$. The final minute of test varied among treatment groups. Heart rate data during minute of test greater than 20 min were excluded from statistical analyses for the exercise portion (panel A). The frequency of experimental observations per minute of tests was eight or less at min 22 to 25 of No Exercise; at min 22 to 27 of 1-h Exercise; and, at min 22 to 30 of 2-h Exercise (panel B).

interactions of treatment, day of experiment, and minute of test were included in the model. The covariance structures were unstructured for day of experiment and autoregressive first order for minute of test.

Data for all other responses (DMI, water intake, BW, BCS, and back fat thickness) were analyzed with a mixed model including the random effect of cow nested within treatment, the repeated measures of day of ex- periment, and fixed effects of treatment and two-way interaction of treatment $\times$ day of experiment. The covariance structure was autoregressive first order for day of experiment. Changes in BW, BCS, and backfat thickness from d 0 to 60 were analyzed with the mixed model including random effect of cow nested within treatment and fixed effect of treatment. Orthogonal contrasts were as follows: No Exercise vs. 1-h Exercise and 2-h Exercise; and, 1-h Exercise vs. 2-h Exercise.

\section{RESULTS AND DISCUSSION}

\section{Preliminary Work}

Results from preliminary work characterized basal heart rates of cows, helped in the development of the current system, and helped determine rates of walking for exercise training and rate and slope of the walking surface of the treadmill for assessment of physiological responses and fitness (Davidson, 2002). Average basal heart rates of lactating Holstein cows in various activities in the dairy farm ranged from a low of 66 BPM while lying and sleeping or ruminating to $72 \pm 1.6 \mathrm{BPM}$ while standing during eating, drinking, ruminating or milking. Somewhat lower average heart rates $(60 \pm 2.1$ $\mathrm{BPM}$ ) were recorded for cows standing at rest in tie stalls before their exercise training session commenced. In preliminary evaluation, increasing the rate of walking from 3.6 to $4.0 \mathrm{~km} / \mathrm{h}$ or the duration from 1 to $2 \mathrm{~h}$ of continuous exercise training in the mechanical walker increased average heart rates. There was no interaction of rate and duration of exercise training on heart rate. The average increase in heart rates above resting values due to exercise training in the mechanical walker was similar among all cows regardless of rate or duration of exercise (average increase $=32 \pm 3.2 \mathrm{BPM}$ ).

In preliminary evaluation of the treadmill system, the maximum rate of walking at a comfortable gait for nonpregnant, nonlactating cows was about $5 \mathrm{~km} / \mathrm{h}$ for 10- to 30-min intervals. Increasing workload on the treadmill by increasing the initial time ( 6 vs. $12 \mathrm{~min}$ ) of walking at $0 \%$ slope or by increasing the slope $(0.8$ vs. $1.6 \%$ ) of the walking surface at 3-min intervals after the initial walking time at $0 \%$ slope affected the length of the treadmill test (length of time cows were willing or able to continue the test). With greater slope increase (1.6 vs. $0.8 \%)$ the time to end of test was shortened (21 vs. $31 \pm 1.1 \mathrm{~min}$ ), indicating greater work challenge at the steeper slope. Additionally, it was decided that length of time of treadmill tests should be evaluated as an index of fitness in subsequent studies. Changes in heart rate during both exercise training in the mechanical walker or treadmill testing reflected the amount of exertion or the amount of power required or expended to do the work. The overall relationship between heart 


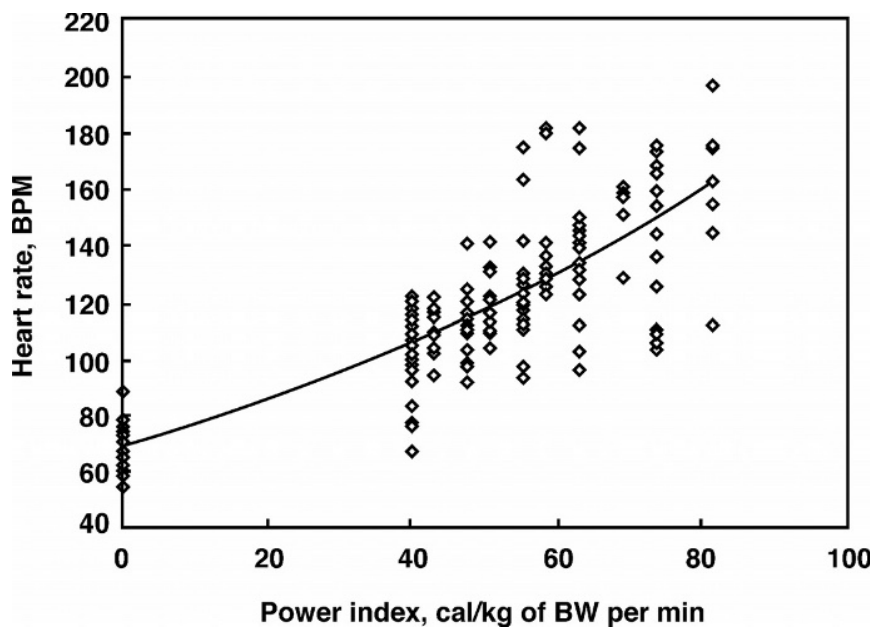

Figure 4. Heart rate during treadmill exercise versus power index for individual cow observations $(\diamond)$. The curve represents the quadratic response of heart rates to the power indices during treadmill exercise. The equation of the regression was $0.0033 \pm 0.0017 \times$ (power index $)^{2}+0.79 \pm 0.14 \times($ power index $)+68.9 \pm 2.9 ; R^{2}=0.70 ; P<0.001$.

rate and calculated power index $(\mathrm{cal} / \mathrm{kg}$ of $\mathrm{BW} \cdot \mathrm{min})$ resulting from walking and slope increases during treadmill tests is in Figure 4. Heart rates increased with increasing power index in a curvilinear fashion $\left(\mathrm{R}^{2}=0.70, P<0.001\right)$. Thus, heart rate was assumed to be an index of fitness that should be evaluated further in future research as the system was developed and assessed.

\section{Effect of Exercise Training on Physical Fitness Indices}

In this experiment, indices of fitness from data collected during the treadmill tests in response to exercise training were computed and evaluated statistically. Indices for each cow and test included: 1) time to end of treadmill test at which maximal heart rate was recorded; 2) maximum heart rate when the treadmill test ended and change in heart rate from 0 to $18 \mathrm{~min}$, and from $0 \mathrm{~min}$ to end of test for each test of each cow; and, 3) plasma L-lactate concentrations when maximal heart rate was recorded, and change in lactate concentrations from 0 to $18 \mathrm{~min}$, and from $0 \mathrm{~min}$ to end of test for each test of each cow (Table 1).

Time to end of treadmill tests. Pooled across day of experiment, time to end of test was about $11 \%$ greater for cows that exercised compared with cows that did not exercise (Table $1 ; P<0.05$ ); whereas, sheep trained at greater workloads than the cows of the current study had a $40 \%$ increase in the length of time of exercise test compared with values before training (Mundie et al., 1991). The interaction of treatment $\times$ day of experi- ment did not affect the length of time of treadmill tests $(P>0.15)$. The ability to continue the treadmill test for greater lengths of time was one indicator that physical fitness was improved for dairy cows in response to previous exercise training. However, exercise training (1-h or 2-h exercise vs. no exercise) did not affect success of completing maximal workloads of treadmill tests (heart rates greater than $165 \mathrm{BPM}$ ) (chi-square analysis, $P$ $>0.15$ ).

The estimates of among- and within-cow variances of time to the end of test were 0.23 and 14.95 , respectively. Using a total estimated variance of 15.18 and power of $90 \%$ for a two-tailed Type I error of 5\% (t-statistic), a minimum of 14 observations per treatment would be required in future experiments to measure a potential mean difference of $5 \mathrm{~min}$.

As indices of fitness during treadmill tests, no differences in heart rates or plasma L-lactate concentrations at the end of the exercise portion of the test (at or near maximum workloads) were detected among exercise training treatments (Table 1). However, there was a strong tendency for an interaction of exercise training treatment $\times$ treadmill test day $(P<0.06)$. Within no exercise treatment there was little difference in plasma lactate concentrations across treadmill test days: 3.45 , $3.67,3.61$, and $3.67 \pm 0.60 \mathrm{mmol} / \mathrm{L}$ for d $15,30,45$, and 60 , respectively. However, in the 1-h Exercise treatment plasma lactate concentrations $(4.90,3.37,3.67$, and $2.66 \mathrm{mmol} / \mathrm{L}$ ) declined during treadmill tests on $\mathrm{d}$ $15,30,45$, and 60 , respectively, in response to progressive exercise training. Similarly, but more markedly, in the 2-h exercise treatment lactate concentrations during treadmill tests declined overall as time in training increased $(3.41,4.00,2.58$, and $2.62 \mathrm{mmol} / \mathrm{L}$ with $15,30,45$, and $60 \mathrm{~d}$ of exercise training, respectively). The decline in plasma lactate as training time increased in 1- and 2-h exercise treatments, but not in No Exercise treatment indicated that cows became more fit as exercise training progressed.

No differences in change in heart rates or plasma lactate concentrations from 0 to $18 \mathrm{~min}$ or from $0 \mathrm{~min}$ to end of treadmill tests were detected among exercise training treatments.

\section{Effects of Exercise Training on Response Patterns During Treadmill Tests}

Although heart rates or plasma lactate concentrations at the end the treadmill tests give single estimates of indices at or near maximal animal response to work, they do not provide insight as to the overall pattern of responses over the course of the treadmill test. Intuitively, responses by the end of the test would be related and correlated with responses earlier in the test, but 
Table 1. Indices of fitness: time to end of treadmill test; heart rates and plasma lactate concentrations at min 0 (rest), min 18 , and end of treadmill test of each cow and test; and, change in heart rates and lactate concentrations from min 0 to 18 min, and from min 0 to end of treadmill test. ${ }^{1}$

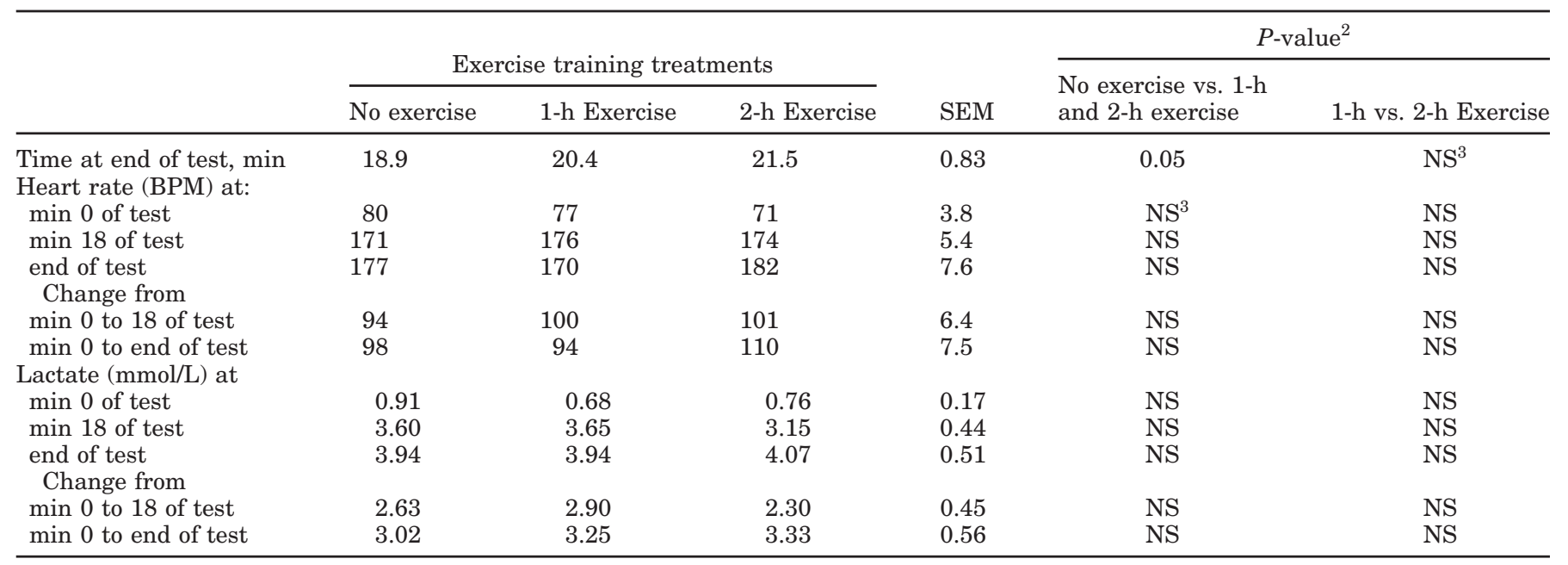

${ }^{1}$ Values are least squares means.

${ }^{2}$ Orthogonal contrasts.

${ }^{3} \mathrm{NS}, P>0.15$.

would be based on much fewer data. Therefore, it was potentially instructive to evaluate the patterns, rate, and extent of responses across the entire span of each treadmill test, including during the time of exercise as well as after the exercise portion of tests.

Heart rates during the exercise portion of treadmill tests. Cardiac output is a function of stroke volume and frequency of strokes. During exercise as heart rates increase, cardiac output increases. The capacity of a subject to maintain exercise is dependent on heart rate and increased cardiac output.

Figure 5 shows the patterns of heart rates for no exercise and 1- and 2-h exercise (pooled) treatments over the time course of the treadmill tests. Responses of 1- and 2-h treatments across time were not different. Regardless of treatment or day of experiment, heart rates during the exercise portion of the treadmill test increased as minute of test increased $(P<0.0001)$. The magnitude of increase of heart rates as a function of minute of test for cows in 1- and 2-h Exercise treatments was less on d 45 and 60 of the experiment compared with that of cows that did not exercise $(P<0.05$; Figure $5)$. Overall, at similar workloads of the treadmill test, cows that exercised every other day for $60 \mathrm{~d}$ for 1 or 2 $\mathrm{h}$ had lower heart rates compared with cows that did not exercise. Similarly, after chronic exercise, the heart rates of calves during exercise challenge were lower compared with pre-training values (Fosha-Dolezal and Fedde, 1988). In the current study, exercise training resulted in lower magnitude of change (increase) of heart rates during treadmill tests on $\mathrm{d} 45$ and 60, indicating that physical fitness of cows was improved.
In the current experiment, the among-cow variance of heart rates during the exercise portion of tests on the treadmill was 175 , and the within-cow variances for each day of the experiment were 3067, 3882, 4198, and 3063 for d 15,30,45, and 60, respectively.

Heart rates during postexercise portions of treadmill tests. Regardless of exercise training treatment, heart rates declined rapidly during the postexercise portion of the treadmill test $(P<0.0001$; Figure 5). As illustrated in Figure 5, pooled across 1- and 2-h exercise treatments vs. no exercise, the interaction of treatment $\times$ day of experiment also affected heart rates $(P<0.05)$.

The rapid decline in heart rates of cows within $3 \mathrm{~min}$ postexercise was similar among treatments (Figure 5). Heart rates returned within 6 min after cessation of exercise to values similar to those at the beginning of the exercise portion of the test. Similar rapid declines in heart rates were measured in horses (Ehrlein et al., 1973). In the current system with dairy cows, the pattern and extent of decline in heart rates during the postexercise portion of the test was quite precipitous with small variability, and not different among treatments. Therefore, as part of this system, postexercise heart rates are not considered helpful in definitive assessment of physical fitness.

Plasma lactate concentrations during treadmill tests. During progressively increasing exercise, anaerobic metabolism of glucose by muscle tissue results in increased plasma L-lactate concentrations (Perrson, 1983). Therefore, reduced plasma lactate concentrations during exercise may be one indicator of greater 

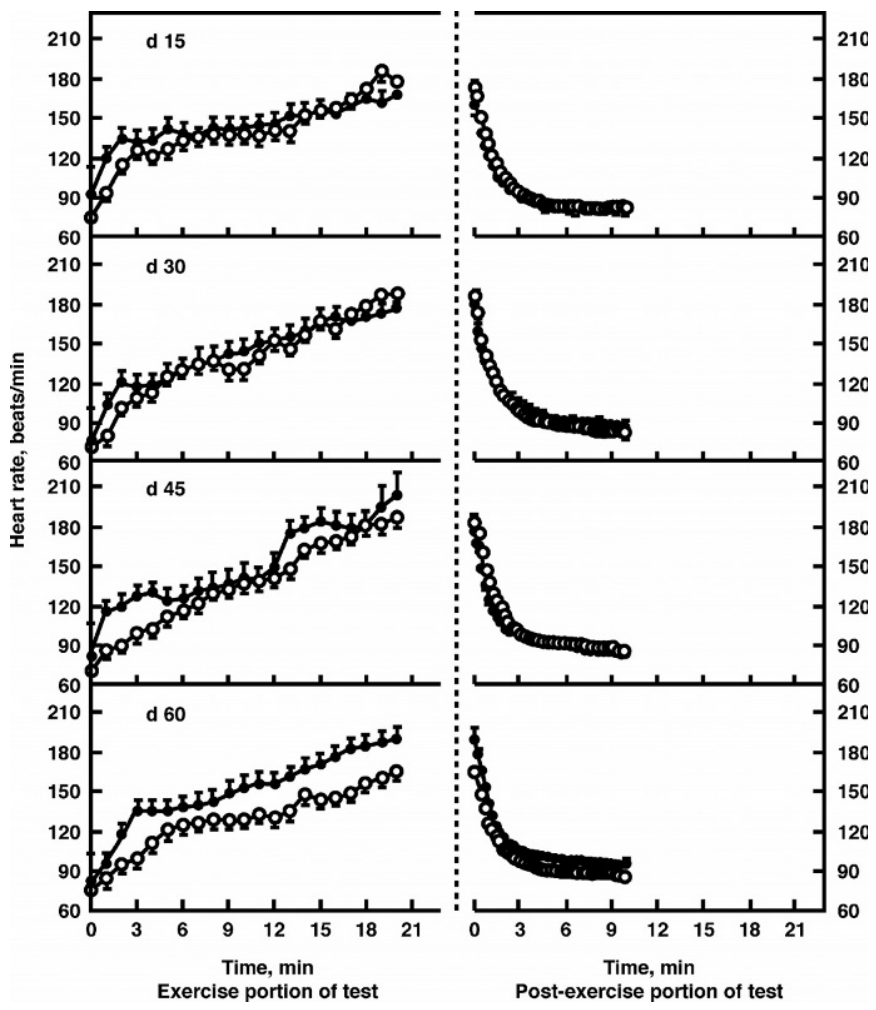

Figure 5. Heart rates of cows during exercise and postexercise portions of treadmill tests on d 15, 30, 45, and 60 of the experiment (least squares means and SEM). Results were pooled exercise (1-h Exercise and 2-h Exercise, $\bigcirc$ ) and No Exercise (๑). Interactions of treatment $\times$ day of experiment, treatment $\times$ minute of test, and treatment $\times$ minute of test affected the magnitude of increases in heart rates during the exercise portions of the test $(P<0.05)$. Interaction of treatment $\times$ day of experiment affected the decline of heart rates during postexercise of the test $(P<0.05)$.

oxidative capacity of muscle. Physical fitness during exercise could be assessed by the maintenance of oxidative metabolism as indicated by plasma lactate concentrations.

There were no differences in L-lactate concentrations across time of test between 1- and 2-h Exercise treatments; therefore, these results are pooled (Figure 6). During the exercise portion of the treadmill test, plasma L-lactate concentrations increased as minute increased on d 15, 30, 45, and 60 of the experiment $(P<0.0001)$. The pattern of increase of L-lactate concentrations of cows in 1- or 2-h Exercise was similar across minutes of the treadmill tests on d 30,45,and 60. However, as day of experiment progressed to $\mathrm{d}$ 60, the L-lactate concentrations of cows in No Exercise increased more within a test than for cows in pooled 1- and 2-h Exercise treatments $(P<0.05$; Figure 6$)$. Similarly, in horses trained for $5 \mathrm{wk}$, plasma venous lactate concentrations were less during an exercise test compared with values before training (Rodiek et al., 1987).
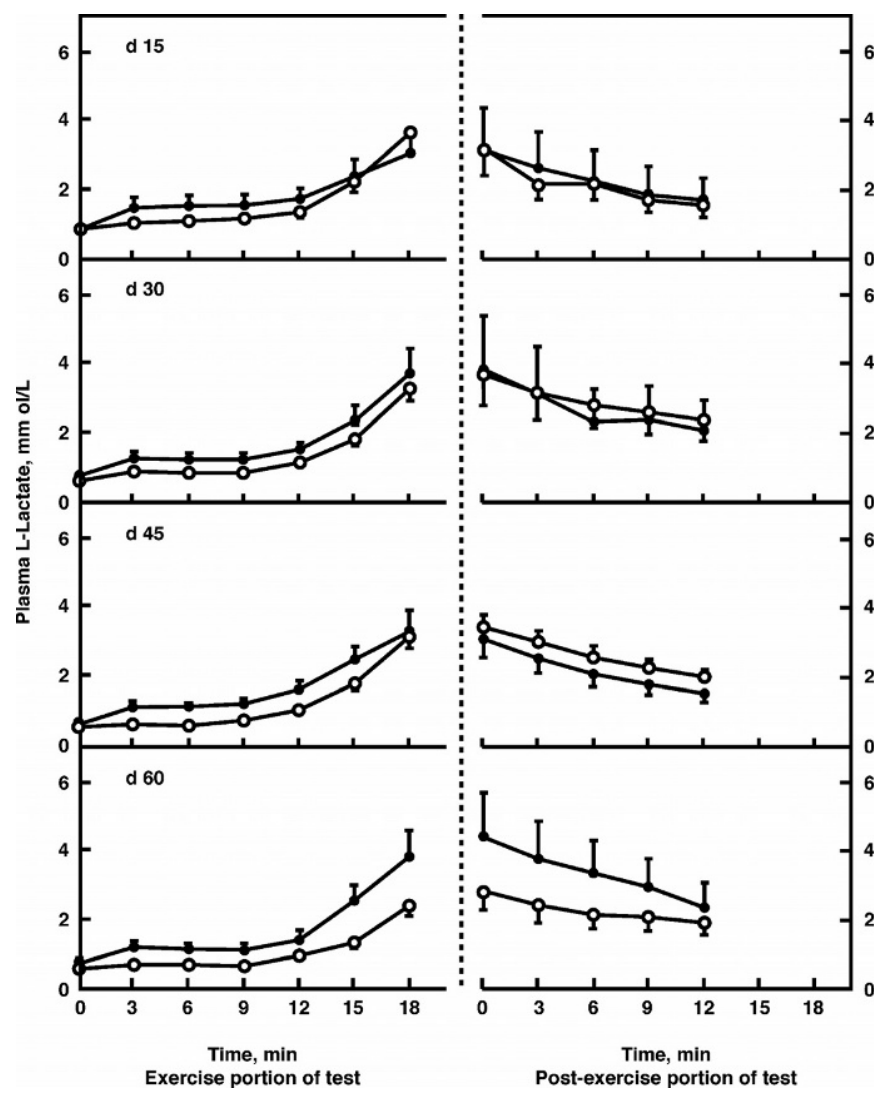

Figure 6. Plasma L-lactate concentrations during exercise and postexercise portions of treadmill tests on $\mathrm{d} 15,30,45$, and 60 of the experiment (back-transformed least squares means and $67 \%$ confidence intervals). Results were pooled across exercise (1-h Exercise and 2-h Exercise, $\bigcirc$ ) vs. No Exercise (-). Main effects of treatment, day of experiment, and minute of test, and the interaction of treatment $\times$ minute of test affected the magnitude of increases of plasma lactate concentrations during the exercise portion of the test $(P<$ $0.05)$. Interaction of treatment $x$ day of experiment by minute of test tended to affect the decline of plasma lactate concentrations during postexercise portions of the test $(P=0.11)$

During the postexercise portion of the treadmill tests, plasma L-lactate concentrations declined overall as minute of test increased $(P<0.0001$; Figure 6$)$. Day of experiment $\times$ minute of test interaction affected the pattern of decline in L-lactate concentrations $(P<0.05)$. Also, lactate concentrations tended to be influenced $x$ the interaction of treatment by minute of test $(P=0.06)$; however, there were not differences in pattern between 1- and 2-h Exercise treatments over time. When data of 1 and 2-h Exercise treatments were pooled, the day of experiment and minute of test tended to affect plasma lactate concentrations $(P=0.11$; Figure 6$)$. By d 60 , cows in 1- or 2-h Exercise treatments had lower plasma lactate concentrations than cows in No Exercise. This indicated that accumulation of lactate in plasma (or the lack of accumulation) was another indicator that can 


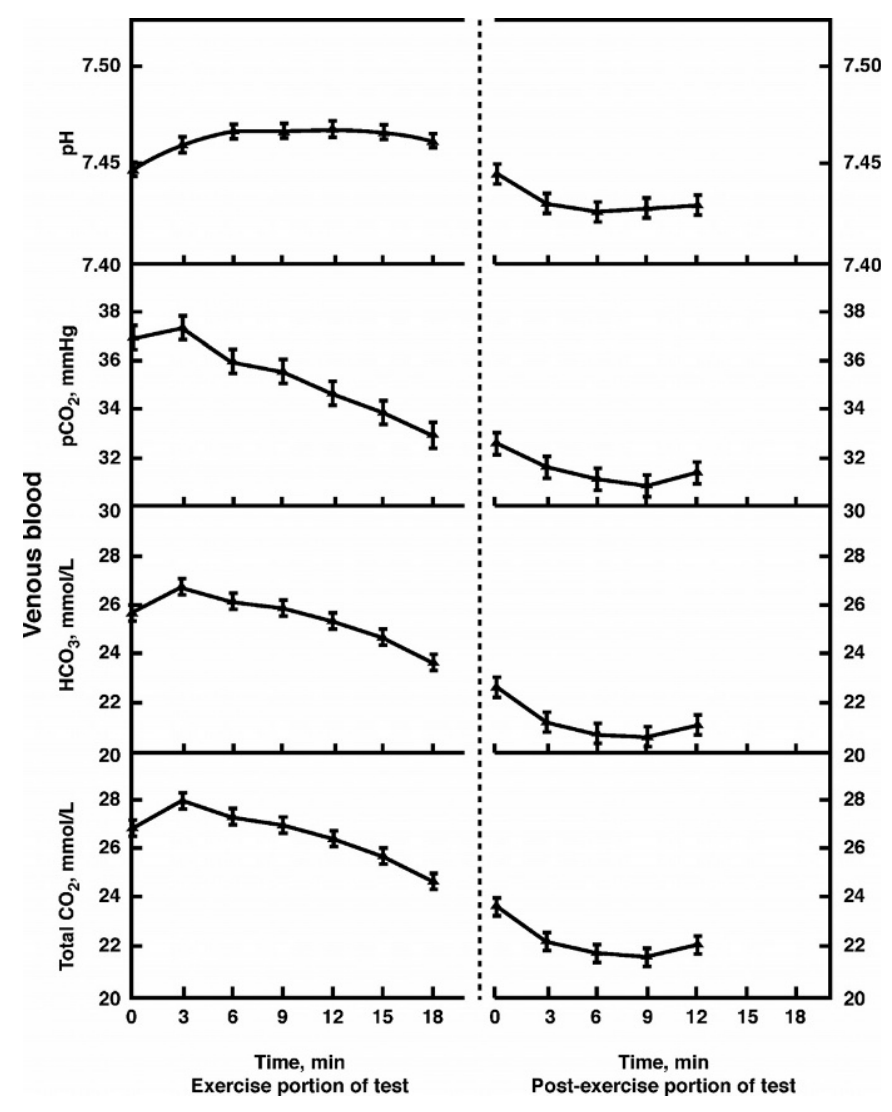

Figure 7. Blood $\mathrm{pH}, \mathrm{pCO}_{2}, \mathrm{HCO}_{3}{ }^{-}$, and $\mathrm{TCO}_{2}$ concentrations during exercise and postexercise portions of treadmill tests pooled across treatment groups and day of experiment (least squares means and SEM). Minute of test affected responses of all variables during exercise and postexercise portions of the test $(P<0.05)$.

be used to assess physical fitness of dairy cows in our system.

For plasma lactate concentrations transformed using natural logarithms, the among-cow variance was 0.0086 , and the within-cow variances for each test of the experiment were $0.0358,0.0252,0.0187$, and 0.0271 for $\mathrm{d} 15,30,45$, and 60 , respectively. Based on a total estimated variance of 0.0444 and power of $90 \%$ for a two-tailed Type I error of 5\% (t-statistic), a minimum of 16 observations per treatment would be required to measure a potential mean difference of $0.25 \mathrm{mmol} / \mathrm{L}$ in L-lactate in the system (natural logarithm value).

Acid-base status during treadmill tests. Overall, exercise training treatments or the interaction of treatment $\times$ time did not affect measurements of acid-base status during the treadmill test. However, pooled across exercise training treatments time in treadmill test affected acid-base responses (Figure 7; $P<0.05$ ). Similar patterns in venous plasma $\mathrm{pH}, \mathrm{pCO}_{2}$, and $\mathrm{HCO}_{3}{ }^{-}$concentrations with acute exercise were detected for horses during exercise tests (Taylor et al., 1995). Additionally,
Judson et al. (1983) described a decline in plasma $\mathrm{HCO}_{3}{ }^{-}$concentrations after exercise of horses with concentrations returning to preexercise values within 15 min postexercise. For the cows in our system, sampling for longer than 12 min postexercise apparently was required for acid-base measurements to return to preexercise test values.

Responses of venous $\mathrm{pCO}_{2}$ during exercise differed among other studies. For mature steers (Jones et al., 1989) and calves (Kuhlmann et al., 1985), venous $\mathrm{pCO}_{2}$ increased as speeds of work increased (increased workloads). In both of these studies, the duration of exercise at various speeds was 5 to $6 \mathrm{~min}$. Similar to the current study, blood $\mathrm{pCO}_{2}$ of sheep decreased after exercising for 25 min compared with resting values (Pethick et al., 1991). The difference in response of $\mathrm{pCO}_{2}$ between these studies and the current study likely was due solely to the differences of duration of exercise.

In the current study, the relatively small blood acidbase measurement changes may reflect the net effects of the simultaneous occurrences of metabolic acidosis and respiratory alkalosis to sustain physiological $\mathrm{pH}$ and acid-base homeostasis. Respiratory rates were not measured in the current study. However, Arave et al. (1987) reported an increase above basal of 40 to 70 breaths per minute of 2-yr old Holstein heifers after 30 min of exercise at $1.5 \mathrm{~km} / \mathrm{h}$ up a $9 \%$ slope. Crossbred beef heifers and steers walking at $2.88 \mathrm{~km} / \mathrm{h}$ had increased respiration frequency over resting values (approximately 25 to 60 breaths/min; Kuhlmann et al., 1985; Piguet et al., 1994). During exercise in the current study, the increased plasma lactate concentrations suggest metabolic acidosis, whereas the changes of $\mathrm{pCO}_{2}$ suggest respiratory alkalosis.

Calculations of BE-ECF and BE-B were an attempt to separate the metabolic and respiratory influences on acid-base status (Fencl and Leith, 1993). Base excess of extracellular fluid and BE-B were calculated as the amount of base needed to adjust blood $\mathrm{pH}$ to 7.4 at a standardized $\mathrm{pCO}_{2}$ of $40 \mathrm{~mm} \mathrm{Hg}$. These calculations are a function of $\mathrm{HCO}_{3}{ }^{-}$concentrations, which were determined from the $\mathrm{pCO}_{2}$ and $\mathrm{pH}$ analyzed in blood. As would be expected, minute of exercise and postexercise portions of treadmill tests affected BE-ECF and BE-B in a similar manner as $\mathrm{pCO}_{2}$, and $\mathrm{TCO}_{2}, \mathrm{HCO}_{3}{ }^{-}$concentrations (Figure 8). However, these calculated concentrations of base excess are questionable indicators of acid-base status when $\mathrm{pCO}_{2}$ varies greatly from $40 \mathrm{~mm}$ $\mathrm{Hg}$ (Fencl and Leith, 1993), as is the case in the current study. Therefore, it is unlikely that the effects of metabolic acidosis and respiratory alkalosis can be separated in the current system without using additional assessments of the respiratory system. In our system, changes of acid-base status $\left(\mathrm{pH}, \mathrm{pCO}_{2}, \mathrm{HCO}_{3}^{-}\right.$, $\mathrm{TCO}_{2}, \mathrm{BE}-\mathrm{ECF}$, 

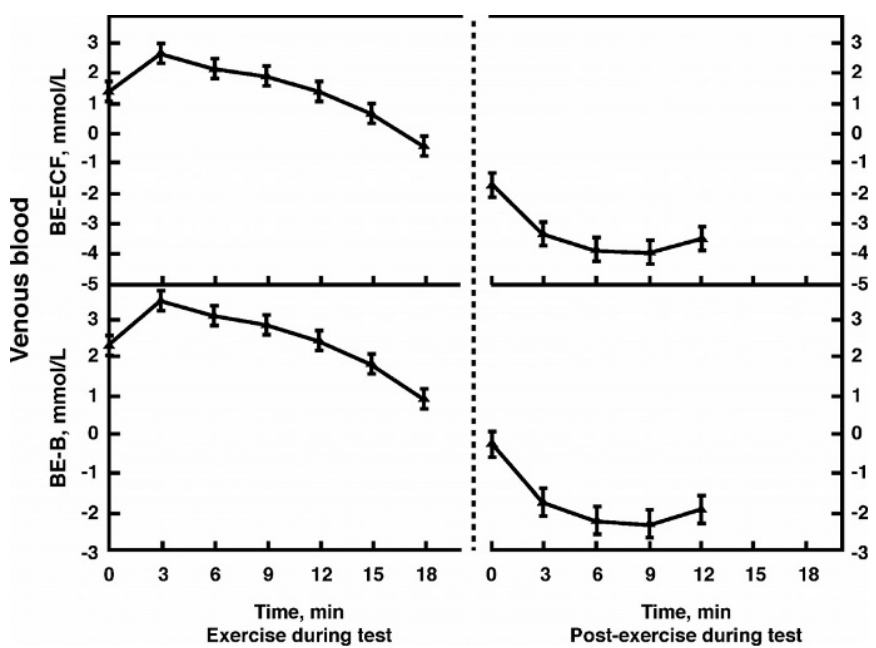

Figure 8. Base excess of extracellular fluid (BE-ECF) and of blood (BE-B) concentrations during exercise and postexercise portions of treadmill tests pooled across treatment groups and day of experiment (least squares means and SEM). Minute of test affected concentrations during exercise and postexercise portions of the test $(P<0.05)$

and $\mathrm{BE}-\mathrm{B})$ were not considered useful indicators of physical fitness because of lack of differences among cows in exercise training treatments.

Hematocrit and hemoglobin during treadmill tests. Changes in hematocrit and HGB concentrations are potential indicators of the oxygen-carrying capacity of the blood. Exercise training treatments did not affect HCT and HGB concentrations. Hematocrit and HGB changes were slight in response the time of treadmill test (Figure 9; $P<0.05$; pooled across exercise treat-

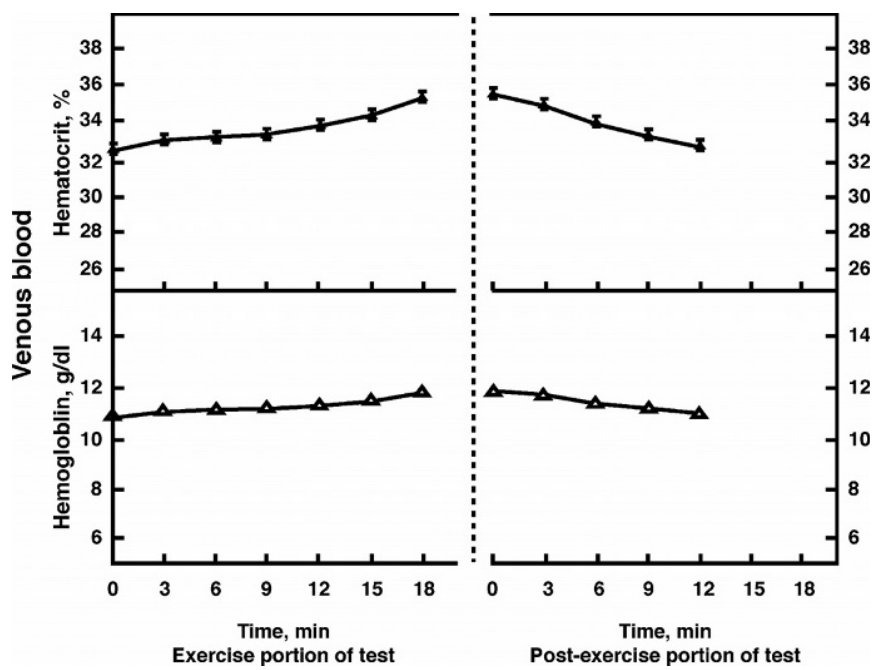

Figure 9. Blood hematocrit and hemoglobin concentrations during exercise and postexercise portions of treadmill tests pooled across treatment groups and day of experiment (least squares means and SEM). Minute of test affected responses during exercise and postexercise portions of the test $(P<0.05)$. ments). Similarly, in calves, HCT increased as speeds of exercise increased (Kuhlmann et al., 1985). Following exercise of dairy cows and steers, packed cell volumes were greater than resting values (Blum et al., 1979; Blake et al., 1982). In the current study, HCT and HGB concentrations in the postexercise interval returned to preexercise values.

Mineral element concentrations during treadmill tests. Minute of exercise and postexercise portions of treadmill tests affected $\mathrm{K}^{+}, \mathrm{Cl}^{-}$, and $\mathrm{iCa}^{2+}$ concentrations $(P<0.05$, Figure 10$)$, whereas exercise training treatments did not. Changes of $\mathrm{Cl}^{-}$and $\mathrm{iCa}^{2+}$ concentrations were very small over the entire treadmill test. During postexercise, concentrations of $\mathrm{iCa}^{2+}$ returned to values near those before exercise; however, $\mathrm{Cl}^{-}$concentrations continued to increase slightly though numerical change is small.

Most markedly, concentrations of blood $\mathrm{K}^{+}$increased about $25 \%$ as time during exercise progressed and then declined to initial concentrations during the postexercise phase of the treadmill test (Figure 10). Similarly, $\mathrm{K}^{+}$increased as exercise speed increased in calves (Kuhlmann et al., 1985; Fosha-Dolezal and Fedde, 1988). Potassium is released from contracting cells during exercise. Previously, Fosha-Dolezal and Fedde (1988) demonstrated that training of calves reduced the magnitude of increases of serum $\mathrm{K}^{+}$concentrations during exercise at a given speed compared with pretraining values. In dogs, training increased the intracellular concentration of $\mathrm{K}^{+}$and $\mathrm{Na}^{+}-\mathrm{K}^{+}$-ATPase activity, which may be involved with reduced concentrations of circu-
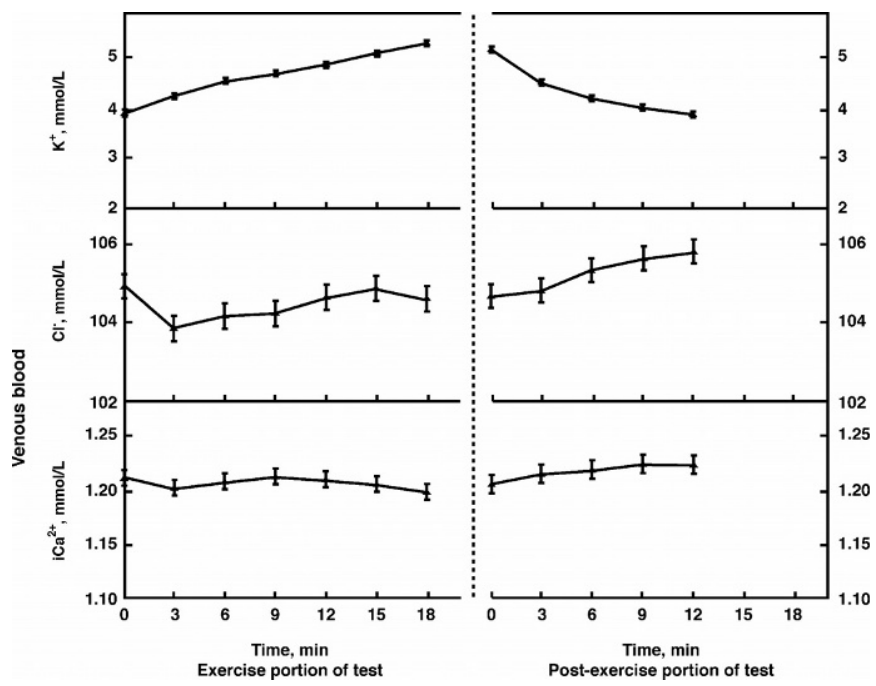

Figure 10. Blood $\mathrm{K}^{+}, \mathrm{Cl}^{-}$, and ionized $\mathrm{Ca}^{2+}\left(\mathrm{iCa}^{2+}\right)$ concentrations during exercise and postexercise portions of treadmill tests pooled across treatment groups and day of experiment (least squares means and SEM). Minute of test affected concentrations during exercise and postexercise portions of the test $(P<0.05)$. 
lating $\mathrm{K}^{+}$during exercise (Knochel et al., 1985). However, in the current study, exercise training treatments did not alter changes in blood $\mathrm{K}^{+}$during the treadmill test.

Overall, venous blood acid-base status measurements and mineral elements were not markedly affected during either portion of the treadmill test by exercise training treatment. Acid-base status variables did not return to initial values within 12 min postexercise, indicating sampling for a longer time postexercise should be done in future experiments. In our system, changes of acid-base status and concentrations of gases and mineral elements in blood were not considered reliable indices of physical fitness.

Estimated among- and within-cow variances of blood gas and mineral element measurements are in Table $1 \mathrm{~A}$ of the Appendix.

\section{Effect of Exercise Training on Water Intake and DMI, BW and BCS}

Exercise training treatments or the interaction of treatment and day of experiment did not affect daily water intake and feed DMI. Average water intake pooled across treatments was $38.7 \pm 4.0 \mathrm{~L} / \mathrm{d}$. Average DMI was $13.7 \pm 0.8 \mathrm{~kg} / \mathrm{d}$ or $1.8 \pm 0.11 \mathrm{~kg} / 100 \mathrm{~kg}$ of BW. Exercised crossbred lactating dairy cows had greater water intakes compared with nonexercised cows, but DMI and milk production were not different (Benedetti et al., 1990). In several other studies using high-forage diets, exercise training did not affect DMI (Anderson et al., 1979; Lamb et al., 1979, 1981; Matthewman et al., 1993). High roughage diets may be fill-limiting, thus masking the possibility that exercise training could increase DMI in response to greater workloads and energy requirements. It remains to be studied in our system whether DMI will increase with greater energy requirements resulting from increased workloads with exercise training when less filling or more energy-dense diets are fed.

Body weights at the beginning $(751 \pm 22 \mathrm{~kg})$ or end $(783 \pm 22 \mathrm{~kg}$ ) of the 60 -d experimental period were not different among treatments. On average, cows in each treatment gained BW during the 60-d experiment. The change in BW from beginning to end of the experiment was different for cows in No Exercise versus those in 1- and 2-h Exercise treatments (52 vs. 32 and $13 \pm$ $11 \mathrm{~kg}$, respectively; $P<0.03$ ). Average beginning and ending BCS of cows pooled across treatments were 3.6 \pm 0.15 and $3.5 \pm 0.15$, respectively, and not affected by exercise training treatments. Change in BCS from beginning to end of the experimental period tended to decline with 1- and 2-h Exercise treatments compared with No Exercise $(-0.13,-0.19$, vs. $0.06 \pm 0.10$, respec- tively; $P<0.10)$. Treatments did not affect beginning $(0.38 \pm 0.06 \mathrm{~cm})$, ending $(0.37 \pm 0.06 \mathrm{~cm})$, or change $(-0.01 \pm 0.04)$ in back fat thickness of cows from 0 to $60 \mathrm{~d}$ of the experiment. There were no interactions of treatment $\times$ day of experiment on BW, BCS, or back fat thickness $(P>0.15)$.

\section{CONCLUSIONS}

A system was developed for dairy cows to possibly affect physical fitness through exercise training using a mechanical walker and to assess potential physiological indicators of fitness during periodic treadmill tests administered over the course of training ( $60 \mathrm{~d})$. Measurements from individual cows of indices of fitness made as single point estimates at the end of treadmill tests at maximal heart rates included: time to end of treadmill test at which maximal heart rate was recorded; maximum heart rate when the treadmill test ended and change in heart rate from 0 to $18 \mathrm{~min}$, and from $0 \mathrm{~min}$ to end of test for each test of each cow; and, plasma Llactate concentrations when maximal heart rates were recorded, and change in lactate concentrations from 0 to $18 \mathrm{~min}$, and from $0 \mathrm{~min}$ to end of each test of each cow. Cows in either 1- or 2-h exercise training treatments had longer times to end of treadmill tests at the time when maximal heart rates were recorded than cows in No Exercise, indicating greater physical fitness. Maximum heart rates when treadmill tests ended or change in heart rates during the course of treadmill tests, or plasma lactate concentrations at maximal heart rates or change in concentrations over the course of the treadmill test as single-point estimates did not indicate improved physical fitness due to exercise training in this system.

When all data from the four treadmill tests (repeated measures effect of day of test) were evaluated by assessing the patterns of responses during the treadmill test (repeated measures effect of minute of test) improvement in physical fitness of cows in exercise training was detected for some measurements compared with No Exercise. Reductions of heart rates and plasma lactate concentrations were apparent after $45 \mathrm{~d}$ of exercise training with the greatest magnitude of difference at $60 \mathrm{~d}$ between exercised and nonexercised cows. Acidbase status variables and mineral element concentrations were not affected in cows that had improved physical fitness as indicated by lower heart rates and plasma L-lactate concentrations over the course of the treadmill tests. Acid-base and mineral element concentrations are not considered useful measurements of fitness in this system.

Changes of heart rates and plasma lactate concentrations over the time course of treadmill tests quantified 
the physical fitness of dairy cows and can be used to compare potential responses to various exercise training treatments or possibly to different management approaches. Except for time to end of test, indices measured as single-point estimates at maximum heart rates at the end of treadmill tests were not reliable indicators of fitness in this system with dairy cows. The amongand within-cow variances estimated for measurements made in this study are useful for the design of future experiments.

\section{ACKNOWLEDGMENTS}

The authors acknowledge the special assistance of Emilly Wilson, Denise Altemose, and Mike Hoagg as well as the help of many other undergraduate students. Financial support of the C. E. Meadows Endowment is gratefully acknowledged.

\section{REFERENCES}

Anderson, M. J., R. C. Lamb, and J. L. Walters. 1979. Effect of prepartum exercise on feed intake and milk production of multiparous cows. J. Dairy Sci. 62:1420-1423.

Arave, C. W., R. C. Lamb, and J. L. Walters. 1987. Physiological and glucocorticoid response to treadmill exercise of Holstein heifers. J. Dairy Sci. 70:1289-1293.

Benedetti, E., H. M. Silva, and R. P. Rocha. 1990. Walking trials with dairy cows: Effect on voluntary water intake. Arq. Bras. Med. Vet. Zoot. 42:39-48.

Blake, J. T., J. D. Olsen, J. L. Walters, and R. C. Lamb. 1982. Attaining and measuring physical fitness in dairy cattle. J. Dairy Sci. 65:1544-1555.

Blum, J. W., W. Bianca, F. Naf, P. Kunz, J. A. Fischer, and M. Da Prada. 1979. Plasma catecholamine and parathyroid hormone responses in cattle during treadmill exercise at simulated high altitude. Horm. Metab. Res. 11:246-251.

Davidson, J. A. 2002. Metabolic and physiological adaptations of late pregnant dairy cows to exercise training. Ph.D. Diss., Michigan State Univ., East Lansing.

Ehrlein, H. J., H. Honicke, W. V. Engelhardt, and G. Tolkmitt. 1973. Heart frequency during standardised exercise as a measure of the working capacity of horses. Zentralbl. Veterinaermed. Reihe A. 20:188-208.

Fencl, V., and D. E. Leith. 1993. Stewart's quantitative acid-base chemistry: Applications in biology and medicine. Respir. Physiol. 91:1-16.

Fosha-Dolezal, S. R., and M. R. Fedde. 1988. Serum potassium during exercise in Hereford calves: Influence of physical conditioning. J. Appl. Physiol. 65:1360-1366.
Jones, J. H., K. E. Longworth, A. Lindholm, K. E. Conley, R. H. Karas, S. R. Kayar, and C. R. Taylor. 1989. Oxygen transport during exercise in large mammals I. Adaptive variation in oxygen demand. J. Appl. Physiol. 67:862-870.

Judson, G. J., G. J. Mooney, and R. S. Thornbury. 1983. Cardiovascular response to exercise in the horse: A review. Pages 354-370 in Equine Exercise Physiology. D. H. Snow, S. G. B. Perrson, and R. J. Rose, eds. Burlington Press Ltd., Cambridge, UK.

Knochel, J. P., J. D. Blachley, J. H. Johnson, and N. W. Carter. 1985. Muscle cell electrical hyperpolarization and reduced exercise hyperkalemia in physically conditioned dogs. J. Clin. Invest. 75:740-745.

Kuhlmann, W. D., D. S. Hodgson, and M. R. Fedde. 1985. Respiratory, cardiovascular, and metabolic adjustments to exercise in the Hereford calf. J. Appl. Physiol. 58:1273-1280.

Lamb, D. R. 1984. The nature of exercise physiology. Pages 1-9 in Physiology of Exercise: Responses and Adaptations. 2nd ed. Macmillan Publishing Co., New York, NY.

Lamb, R. C., M. J. Anderson, and J. L. Walters. 1981. Forced walking prepartum for dairy cows of different ages. J. Dairy Sci. 64:2017-2024.

Lamb, R. C., B. O. Barker, M. J. Anderson, and J. L. Walters. 1979. Effects of forced exercise on two-year-old Holstein heifers. J. Dairy Sci. 62:1791-1797.

Matthewman, R. W., J. D. Oldham, and G. W. Horgan. 1993. A note on the effect of sustained exercise on straw intake and body weight in lactating cattle. Anim. Prod. 57:491-494.

Mundie, T. G., A. J. Januszkiewicz, D. B. Rayburn, D. G. Marin, and G. R. Ripple. 1991. Effects of conditioning and maximal incremental exercise on oxygen consumption in sheep. Am. J. Vet. Res. 52:1019-1023.

Perrson, S. G. B. 1983. Evaluation of exercise tolerance and fitness in the performance horse. Pages 441-457 in Equine Exercise Physiology. D. H. Snow, S. G. B. Perrson, and R. J. Rose, eds. Burlington Press Ltd., Cambridge, UK.

Pethick, D. W., C. B. Miller, and N. G. Harman. 1991. Exercise in Merino sheep-the relationships between work intensity, endurance, anaerobic threshold and glucose metabolism. Aust. J. Agric. Res. 42:599-620.

Piguet, M., R. M. Bruckmaier, and J. W. Blum. 1994. Cardio-respiratory, haematological and lactate responses of breeding calves to treadmill exercise. J. Anim. Physiol. Anim. Nutr. 72:101-114.

Rodiek, A. V., L. M. Lawrence, and M. A. Russell. 1987. Cardiovascular effects of intermittent or continuous treadmill conditioning in horses. J. Equine Vet. Sci. 7:14-19.

SAS Software, Release 8.2. 1999. SAS Inst., Inc., Cary, NC.

Taylor, L. E., P. L. Ferrante, D. S. Kronfeld, and T. N. Meacham. 1995. Acid-base variables during incremental exercise in sprinttrained horses fed a high-fat diet. J. Anim. Sci. 73:2009-2018.

VandeHaar, M. J., G. Yousif, B. K. Sharma, T. H. Herdt, R. S. Emery, M. S. Allen, and J. L. Liesman. 1999. Effect of energy and protein density of prepartum diets on fat and protein metabolism of dairy cattle in the periparturient period. J. Dairy Sci. 82:1282-1295.

Wildman, E. E., G. M. Jones, P. E. Wagner, R. L. Boman, H. F. Trout, and T. N. Lesch. 1982. A dairy cow body condition scoring system and its relationship to selected production characteristics. J. Dairy Sci. 65:495-501. 


\section{APPENDIX}

Table 1A. Estimated among and within-variances for blood acid-base variables and mineral element concentrations during the exercise portion of the treadmill test. ${ }^{1}$

\begin{tabular}{llllll}
\hline & & \multicolumn{3}{c}{ Within-cow variances for each test } \\
\cline { 3 - 6 } Dependent variables $^{2}$ & Among-cow variance & $\mathrm{d} 15$ & $\mathrm{~d} 30$ & $\mathrm{~d} 45$ & $\mathrm{~d} 60$ \\
\hline $\mathrm{pH}$ & $9.7 \times 10^{-5}$ & $3.2 \times 10^{-4}$ & $2.8 \times 10^{-4}$ & $2.4 \times 10^{-4}$ & $2.9 \times 10^{-4}$ \\
$\mathrm{pCO}_{2}, \mathrm{~mm} \mathrm{Hg}$ & 2.4 & 12.1 & 9.6 & 6.3 & 9.7 \\
$\mathrm{HCO}_{3}^{-}, \mathrm{mmol} / \mathrm{L}$ & 0.48 & 5.1 & 5.7 & 3.5 & 5.6 \\
$\mathrm{TCO}_{2}, \mathrm{mmol} / \mathrm{L}$ & 0.55 & 5.6 & 6.1 & 3.7 & 6.0 \\
$\mathrm{BE}-\mathrm{ECF}, \mathrm{mmol} / \mathrm{L}$ & 0.37 & 5.2 & 6.4 & 4.0 & 5.9 \\
$\mathrm{BE}-\mathrm{B}, \mathrm{mmol} / \mathrm{L}$ & 0.22 & 3.9 & 5.0 & 3.1 & 4.4 \\
$\mathrm{HCT}, \%$ & 0.61 & 4.5 & 2.7 & 3.7 & 3.5 \\
$\mathrm{HGB}, \mathrm{g} / \mathrm{dl}$ & 0.07 & 0.48 & 0.30 & 0.28 & 0.23 \\
$\mathrm{~K}^{+}, \mathrm{mmol} / \mathrm{L}$ & 0.03 & 0.45 & 0.06 & 0.04 & 0.06 \\
$\mathrm{Cl}^{-}, \mathrm{mmol} / \mathrm{L}$ & 1.7 & 4.1 & 2.0 & 2.4 & 2.3 \\
$\mathrm{iCa}^{2+}, \mathrm{mmol} / \mathrm{L}$ & $4.6 \times 10^{-4}$ & $1.7 \times 10^{-3}$ & $1.2 \times 10^{-3}$ & $2.0 \times 10^{-3}$ & $1.4 \times 10^{-3}$ \\
\hline
\end{tabular}

${ }^{1}$ Covariance structures of repeated measure effects of day of experiment and minute during exercise portions of tests were unstructured and auto-regressive first order.

${ }_{2} \mathrm{pCO}_{2}=$ partial pressure carbon dioxide, $\mathrm{HCO}_{3}{ }^{-}=$bicarbonate ion, $\mathrm{TCO}_{2}=$ total carbon dioxide, $\mathrm{BE}-\mathrm{ECF}$ = base excess of extracellular fluid, BE-B = base excess of blood, HCT = hematocrit, HGB = hemoglobin concentration, $\mathrm{K}^{+}=$potassium ion, $\mathrm{Cl}^{-}=$chloride ion, $\mathrm{iCa}^{2+}=$ ionized calcium ion . 